\title{
A COVID-19 e o distanciamento social: repercussões na saúde mental do grupo de risco
}

\author{
Ana Carolina Paes* \\ Cristiane Barros Marcos** \\ Marciana Zambillo***
}

\begin{abstract}
Resumo
O presente estudo analisou as repercussões da pandemia e do distanciamento social na saúde mental de pessoas do grupo de risco da COVID-19. Por meio de entrevistas com membros de um grupo educativo em saúde, discute-se os entrelaçamentos entre as principais repercussões, os determinantes sociais da saúde e a Saúde Mental. As principais repercussões encontradas foram a sensação de privação de liberdade, insegurança nas informações sobre a pandemia, limitação de acesso a serviços de saúde e aumento das demandas emocionais. Os resultados suscitam a necessidade de repensar estratégias de cuidado em saúde de acordo com o novo contexto.

Palavras-chave: COVID-19; Saúde Mental; Pandemias; Grupos de Risco.
\end{abstract}

\section{COVID-19 and social distance: effects on risk group's mental health}

\begin{abstract}
This study analyzed the repercussions of the pandemic and social distancing on the mental health of people in the risk group of COVID-19. Through interviews with members of a health education group, the interrelationships between the main repercussions, the social determinants of health and Mental Health are discussed. The main repercussions found were the feeling of deprivation of freedom, informational insecurity about the pandemic, limited access to health services and increased emotional demands. The results raise the need to rethink health care strategies according to the new context.
\end{abstract}

Keywords: COVID-19; Mental health; Pandemics; Risk Groups.

* Universidade Federal do Rio Grande - FURG. Especialista em Psicologia da Saúde e Hospitalar pelo Programa de Residência Integrada Multiprofissional Hospitalar com Ênfase em Saúde Cardio-Metabólica do Adulto - RIMHAS. Graduada em Psicologia pela Universidade Federal do Rio Grande - FURG. anacarolina-paes@hotmail.com.

** Universidade Federal do Rio Grande - FURG. Professora Adjunta da Universidade Federal do Rio Grande - FURG. Doutora em Psicologia na Universidade do Vale do Rio dos Sinos/ Unisinos. Mestre em Psicologia (2012) e Graduada em Psicologia (Bacharelado/2007, Formação de Psicólogo/2008 e Licenciatura/2009) pela Universidade Federal de Santa Catarina - UFSC. cristianemarcos@gmail.com .

***Hospital Universitário Dr. Miguel Riet Corrêa Jr. - HU-FURG-EBSERH. Doutoranda e Mestre em Psicologia Social e Institucional pela Universidade Federal do Rio Grande do Sul (UfRGS). Especialista em Saúde Mental Coletiva pelo Programa de Residência em Saúde Mental Coletiva da Escola de Saúde Pública do Rio Grande do Sul - ESP (2017). Graduada em Psicologia pela Faculdade Meridional (2013) e em Filosofia pela Universidade de Passo Fundo (2012).marcianazambillo@gmail.com . 


\section{Introdução}

A Coronavirus Disease 2019 (COVID-19) é causada pelo Coronavírus (SARS-CoV-2), descoberto em 2019, após casos registrados na China. É consenso que se pode contrair a doença através de interação com o vírus a partir de gotículas em contato com mucosas como boca e nariz. Em março de 2020 a Organização Mundial da Saúde (OMS) declarou a situação da COVID-19 como pandêmica, isto é, a disseminação estava por dois ou mais continentes com transmissão sustentada entre as pessoas (OPAS/OMS, 2020).

Populações específicas como os idosos e os portadores de doenças crônicas compõem o grupo de risco por estarem especialmente vulneráveis a desfechos negativos, que incluem variações graves da doença e maior mortalidade (Guan, Ni, Hu \& Liang, 2020). As comorbidades mais prevalentes em pacientes com COVID-19 são diabetes e hipertensão (Guan et al., 2020), doenças que exigem manejo constante, prática de atividade física, alimentação balanceada e controle do estresse (Brasil, 2018), cujo acompanhamento regular se torna difícil em meio às medidas de distanciamento e aumenta as chances de deterioração da saúde (Kar, Arafat, Kabir, Sharma \& Saxena, 2020).

O distanciamento físico entre pessoas é estratégia primordial para o manejo da crise. Para esta pesquisa adotou-se a terminologia distanciamento social, entendendo-o como o afastamento voluntário e a evitação de circulação em espaços coletivos, para controlar a disseminação do vírus (Anderson, Heesterbeek, Klinkenberg \& Hollingsworth, 2020). As restrições incluem a suspensão de serviços não essenciais, envolvendo as instituições de saúde que precisaram suspender algumas atividades.

Diante deste cenário, é compreensível que as pessoas sintam-se inseguras e emocionalmente sobrecarregadas. $\mathrm{O}$ primeiro estudo a analisar a saúde mental da população em geral, encontrou impactos psicológicos imediatos com aumento de sintomas de ansiedade, depressão e estresse (Wang, Pan, Wan, Tan, Xu, Ho, \& Ho, 2020). Impactos do isolamento na saúde mental também resultaram em ansiedade, depressão e estresse (Hossain, Sultana \& Purohit, 2020).

Pessoas com doenças crônicas possuem mais chances de desenvolver problemas de saúde mental do que a população em geral (Helena, Lasagno \& Vieira, 2010). Isso deve-se a fatores como a influência do adoecimento sobre a funcionalidade e a interação social (Portugal,
Campos, Gonçalves, Mari, Gaski, Bower, Dowrick \& Fortes, 2014), dentre outras.

Sendo assim, o objetivo deste estudo é investigar as repercussões da pandemia e do distanciamento social na saúde mental de pessoas com doenças crônicas vinculadas a um serviço de saúde no Rio Grande do Sul. Buscou-se verificar a presença de implicações negativas e analisar a relação entre os determinantes sociais de saúde e a autopercepção de saúde mental dos participantes.

\section{A Pandemia da COVID-19 e a Comunicação de Riscos}

A imprevisibilidade dessa pandemia pode ser exacerbada por mitos, informações equivocadas e mal-entendidos (Bao, Sun, Meng, Shi \& Lu, 2020). A desinformação pode gerar estresse e adoção de comportamentos pouco adaptativos. Nas primeiras semanas da pandemia na China, a circulação de informações falsas induziu a compra e estocagem compulsiva de mercadorias e máscaras (Kar et al., 2020).

A comunicação de riscos é parte integrante da resposta de emergência e envolve oferecer ao público conhecimentos necessários sobre proteção e cuidados (OMS, 2018). Medo, culpa e tristeza podem ser comuns diante de pandemias e faz-se necessário estabelecer uma comunicação eficaz, com informações úteis e atualizadas, para reduzir inseguranças e evitar sobrecarga mental.

\section{Distanciamento Social e Satisfação com a própria vida}

O distanciamento social configurou-se como a principal estratégia para evitar um colapso dos sistemas de saúde. Apesar da necessidade desta medida, ela pode acarretar sofrimento emocional. A Fiocruz (2020) estima que a ocorrência de alguma manifestação psicopatológica pode chegar a afetar de um terço até metade da população exposta a uma epidemia, caso nenhuma intervenção seja feita. Entretanto, nem todo sofrimento psicossocial é patológico, a maioria são reações esperadas diante de uma situação incomum (Fiocruz, 2020).

As reações mais frequentes ao isolamento, incluem: sentimentos de desamparo, tédio, solidão e tristeza (Fiocruz, 2020). O afastamento de familiares e amigos e a incerteza sobre a duração destas medidas podem contribuir para o sofrimento psíquico (Brooks, Webster, Smith, Woodland, Wessely, Greenberg, 2020). Indivíduos que se percebem como afastados de suas redes de apoio, em ge- 
ral, sofrem prejuízos psicossociais, fenômeno preocupante quando as medidas de distanciamento físico são vitais.

\section{Determinantes Sociais de Saúde e Saúde Mental}

A OMS define saúde como um estado de completo bem-estar físico, mental e social, e não, apenas, ausência de doenças. Este conceito ampliado de saúde, implica em como fatores complexos afetam a vida. A saúde mental é parte indivisível da saúde geral, envolvendo aspectos mentais, comportamentais, sociais e culturais, não sendo apenas a ausência de transtornos mentais (OMS, 2018).

Sob a perspectiva do risco psicossocial, considera-se as situações em que os sujeitos estão colocados em seus contextos de vida, que podem desencadear reações prejudiciais (Spink, 2003). Os impactos psicossociais da COVID-19 guardam importante relação com os determinantes sociais de saúde, ou seja, com as condições em que a pessoa vive e trabalha (moradia, alimentação, trabalho), além dos determinantes da saúde mental (pensamentos, emoções, comportamentos) e político-ambientais (proteção social, estilo de vida e apoio comunitário) (OPAS/ OMS, 2018).

Diante do exposto, evidencia-se a relevância deste estudo ao considerar as possíveis repercussões psicossociais destes fenômenos sobre a saúde mental dos participantes, visando compreender como a crise decorrente da pandemia de COVID-19 os tem afetado.

\section{Materiais e método}

Adotou-se uma abordagem qualitativa de caráter exploratório, utilizando o estudo de casos múltiplos. A coleta de dados se deu por entrevistas semiestruturadas online e a análise dos dados a partir da análise de conteúdo de Bardin (Bardin, 2011). O estudo de casos múltiplos envolve mais de um caso e visa compreender como é o mundo da perspectiva dos participantes, a partir de um ponto de vista interpretativo (Alves-Mazzotti, 2006).

Utilizou-se o conceito de autopercepção de saúde, por sua natureza subjetiva e sua associação a outros indicadores de saúde, incluindo aspectos biológicos, psicológicos e sociais, mostrando-se bastante confiável (Jylha, Guralnik, Ferruci, Jokela \& Heikkinen, 1998).

\section{Características do Local e dos Participantes}

O estudo foi desenvolvido em um ambulatório para doenças cardiometabólicas no Rio Grande do Sul, o qual conta com uma equipe multiprofissional. Esta equipe mantém um grupo interdisciplinar destinado a discussão com pacientes a respeito da Síndrome Metabólica e doenças ligadas a ela, sendo assim um espaço de educação em saúde. Este grupo também mantém contato remoto, por meio do whatsapp.

Os participantes foram selecionados por conveniência, de acordo com o modelo multicasos de Robert Stake (2006) que indica entre 4 e 10 casos para garantir representatividade. Portadores de Doenças Crônicas, de ambos os sexos, maiores de 18 anos, residentes no município de realização da pesquisa, vinculados ao ambulatório e membros do grupo educativo em saúde.

\section{Procedimento da coleta de dados}

Após aprovação pela Comissão Nacional de Ética em Pesquisa (CONEP), a pesquisa foi divulgada através do Whatsapp do grupo e realizou-se contato individual com os interessados para agendamento da entrevista. Os selecionados foram direcionados para endereço eletrônico para declaração de concordância através do Termo de Consentimento Livre e Esclarecido.

Os dados foram coletados por meio de entrevistas semiestruturadas individuais através de chamada de vídeo via Whatsapp. Tiveram duração média de 40 minutos e foram audiogravadas e transcritas para análise. O sigilo sobre as informações e o anonimato dos participantes foram garantidos com a ocultação e substituição de nomes por pseudônimos.

A limitação da coleta a somente dados primários ocorreu devido ao distanciamento social que impediu o comparecimento dos participantes para entrevistas presenciais e também ao comprometimento de seus prontuários que não tinham dados atualizados, justamente pela interrupção das frentes de trabalho, o que implica na impossibilidade de cruzar dados de diferentes fontes. Devido ao número de participantes, apesar da possibilidade de transferibilidade, não foi possível descrever a experiência do grupo como um todo, menos ainda da população do grupo de risco.

\section{Instrumentos: Questões de Entrevista}

O formulário de coleta de dados foi produzido pelas pesquisadoras a partir da revisão de literatura sobre as possíveis repercussões da pandemia e do distanciamento social na saúde mental, as principais reações esperadas neste contexto e os determinantes sociais de saúde (OMS, 
2020; Fiocruz, 2020; OPAS/OMS, 2018). Consistiu-se de questões organizadas em quatro seções: (i) dados sociodemográficos, (ii) aspectos psicossociais relacionados à saúde, (iii) autopercepção dos impactos da pandemia e do distanciamento social na saúde mental, e (iv) acesso à informação e serviços de saúde.

\section{Análise de dados}

A partir da construção de categorias analíticas, os dados foram examinados sob a óptica da análise de conteúdo temática. Esta consiste no exame da comunicação para obter indicadores para a compreensão das condições de produção e recepção de mensagens, através de procedimentos sistemáticos e objetivos de descrição de seu conteúdo (Bardin, 2011).

Empregou-se a análise de conteúdo temática, em busca dos núcleos de sentido da comunicação, a partir da presença e frequência de determinados conteúdos que tivessem significado para os participantes (Minayo, 2013). Este procedimento incluiu a leitura flutuante do material, observando a dinâmica entre as suposições iniciais e emergentes e o referencial teórico, seguida pela leitura exaustiva e do confronto com as questões iniciais. A redução do texto em unidades de registro, em que o conteúdo das falas foi organizado a partir de expressões, palavras e temas e relacionado com o que destacou-se na fase anterior; $E$ foram propostas inferências e interpretações a partir do confronto com o referencial teórico (Minayo, 2013).

A partir dos dados obtidos, selecionou-se quatro grandes grupos de respostas e iniciou-se a descrição e análise das falas relacionadas a (1) Distanciamento Social, (2) Informação, (3) Acesso aos Serviços de Saúde e (4) Saúde Mental. Por fim, apresenta-se os resultados em forma de casos individuais e cruzamento entre os casos, buscando garantir maior qualidade na análise, a partir da síntese de casos cruzados, de acordo com Yin (2015).

\section{Resultados}

A pesquisa contou com 4 entrevistados, 2 homens e 2 mulheres com média de idade de 60 anos, todos brancos, com diagnóstico de diabetes tipo II, bem como, no mínimo, uma outra doença relacionada à síndrome metabólica, como hipertensão ou obesidade.

\section{A tabela abaixo agrupa as principais características dos entrevistados:}

\begin{tabular}{c|c|c|c|c|c}
\hline Caso & Sexo & Pseudônimo & Idade & Escolaridade & Ocupação \\
\hline C1 & F & Márcia & 64 & $\begin{array}{c}4^{a} \text { série - Ensino } \\
\text { Fundamental }\end{array}$ & $\begin{array}{c}\text { Aposentada } \\
\text { C2 }\end{array}$ \\
\hline F & Sandra & 62 & $\begin{array}{c}7^{\text {a }} \text { série - Ensino } \\
\text { Fundamental }\end{array}$ & Aposentada \\
\hline C3 & M & Antônio & 62 & Ensino Médio Incompleto & Aposentado \\
\hline C4 & M & Carlos & 51 & Ensino Médio Completo & Contrução Civil \\
\hline
\end{tabular}

\section{Análise Individual dos Casos}

\section{Caso 1}

Márcia considera-se parte do grupo de risco devido a múltiplas doenças crônicas. Reside com o marido, um filho e a nora. Recebe visitas de outro filho e de uma prima. Mostra aderência às estratégias protetivas: "Uso máscara e estou sempre com [álcool] gel na minha bolsa". Entretanto titubeia num aparen- te deslocamento da pandemia: "no meu bairro dizem que tem o COVID, só que eu não tenho contato com nenhum desses que disseram que teve, só vejo falar". Para mais tarde chorar e poder dizer que sente "[...] raiva de ter aparecido essa porcaria". "É triste [choro], eu não gosto nem de pensar".

Em seu discurso o mais difícil tem sido: "Ficar confinada. É isso que derruba a gente", além da redução do contato: "os meus filhos vêm menos aqui". Ela chama 
atenção para o sofrimento dos idosos, grupo ao qual pertence: "está sendo muito difícil para terceira idade [...] quem não morre do COVID, morre da depressão".

As informações sobre a pandemia vem principalmente das redes sociais e são recebidas com desconfiança: "é tanta informação que não se sabe em qual acreditar". A falta de informação segura aparenta estimular fantasias: "[...] tenho muito medo de pegar e ir para o hospital. Porque dizem no Facebook, que é a coisa mais horrível", e endossa o medo do contágio e da possibilidade de internação com morte solitária: "Eu já disse aqui [em casa], se acontecer alguma coisa não me deixem sozinha lá, melhor morrer em casa".

Márcia demonstra insegurança na garantia de acesso aos serviços de saúde: "eles não vão me atender, vão dar preferência pra um com COVID. Se eu tivesse alguma coisa mais grave eu já teria morrido". Em contrapartida demonstra vínculo com o grupo suspenso: "Na reunião [...] eu conversava muito com a [psicóloga]. Eu já tive depressão muito forte e quem me salvou foi o grupo".

Durante a entrevista tem dificuldade em definir sua saúde mental, e diz as estratégias que utiliza: "[suspiro]me distraio muito com crochê. E quando minha prima vem aqui, uma segura na outra, somos muito de conversar". E parece ter dado sentido à ociosidade: "Agora tenho tempo de sobra para me cuidar, antes tinha a correria da rua", e a espiritualidade aparece como elemento protetivo: "[...] Eu tenho muita fé em Deus e me apego a ele. E a cabeça tem que segurar, senão afunda mesmo".

\section{Caso 2}

Sandra considera-se parte do grupo de risco: "porque sou obesa, tenho diabetes e hipertensão". Reside com o marido e encontra presencialmente apenas a família nuclear e, por meio de redes sociais, as filhas e os netos. Sente-se confinada: "Estamos encerrados dentro de casa [...] Tô com saudade das minhas filhas e meus netos [...] não visito ninguém e não recebo ninguém”.

As medidas de distanciamento social alteraram a rotina familiar: "Pagar as contas [...] recebo, trago pra casa e higienizo tudo". Ocasionou também novas divisões de tarefas: "[...] minha nora teve que ficar em casa por causa dos filhos, porque não podia trazer pra mim [cuidar]. E o meu filho teve que ficar à frente das compras". Estas mudanças parecem ter gerado sentimento de aprisionamento, medo e perda da autonomia: "Mudou tudo, hoje nós somos uns presos". "E esse medo de não poder sair pra rua, ser livre e ir onde quiser [...] hoje tudo tem que depender dos outros".

Informa-se sobre a pandemia pelos meios tradicionais, acredita que há excessos e mostra-se angustiada e vulnerável: "é só desgraça [...] a gente se informa e dá angústia do número de pessoas morrendo, parece que nada está sendo feito". Menciona a longevidade como um marcador da experiência de vida e comenta que apesar disso não sabe como agir, "hoje tu não sabe o que tu faz [...] nos meus 62 anos eu nunca tinha passado por uma coisa assim. É um inimigo que tu não vê".

Tem medo de procurar os serviços de saúde e se contaminar: "[...]Imagina se eu vou em uma consulta no hospital? A não ser que eu esteja morrendo". Considera também que o acesso está mais difícil: "Estou sem tratamento, nem uma receita tu consegue. [...] a gente tá bem abandonado". No entanto, a interrupção não desfez o vínculo com o grupo: "[...] eu antes tava aí e tu não tem ideia o quanto eu melhorei [...] sinto falta do grupo, o grupo é muito bom e te ajuda muito, tu aprende muita coisa".

Com relação a sua saúde mental: "[suspiro] Não tá péssimo ainda, tá dando pra segurar. [...] meu medo é de ter que ir para um hospital, seria a pior coisa hoje na vida". E o sentimento de impotência se faz presente: "Fico triste pelas notícias, pelas coisas que a gente vê e não pode fazer nada". Ajustar a alimentação é considerado um desafio no momento: "Tô tentando estar dentro da regra que a nutricionista passou, mas às vezes tu tá triste e tu sai fora. [...] Eu não vou na fruteira buscar pra não estar me arriscando então acabo comendo arroz e pão".

O suporte familiar aparece como protetivo: "a gente se dá bem, então a gente tira de letra isso aí”. E Sandra vê a distância como necessária para a segurança de todos: "tenho dois netos que não posso abraçar [...] a gente sente falta, mas é pro bem de todos, todo mundo seguro é o melhor".

\section{Caso 3}

Antônio têm múltiplas doenças crônicas, porém demonstra incerteza se faz parte do grupo de risco. Reside com a esposa e a filha de 23 anos, com as quais mantém contato presencial e comunica-se com os demais por Whatsapp. A princípio afirma que suas atividades sofreram adaptações: "Eu continuo a mesma coisa, claro que as mesmas atividades eu já não posso fazer [...] então eu faço em casa [...] A gente vai se configurando". Mas ele tem baixa visão e considera complicado adaptar-se: "tem 
que ficar botando máscara e eu uso óculos, embaça tudo e eu não vejo nada, então ou eu tiro a máscara ou eu tiro o óculos, não tem jeito".

Para Antônio, a principal alteração causada pela pandemia é: "o distanciamento social, não poder passear". E a permanência por longo período em casa é motivo de tensão: "O estresse, é direto, já pensou todo dia com a minha mulher aqui me vigiando". Diz decepcionar-se "porque tem um monte de cientistas, um monte de dinheiro envolvido e de repente nem querem inventar uma vacina agora". E segue, sugerindo teorias conspiratórias: "[...] eu vi no youtube, os estados unidos estão fabricando milhares de caixões, é sinal desse negócio de catástrofe [...] pra mim isso é tudo organizado [...] vão matar um pouco aí pra dar um baque na economia".

Sobre o acesso aos serviços de saúde refere que: "Por enquanto não tem atendimento nenhum, não tem médico", e mostra-se receoso diante da situação atual: "se tu vai tem perigo de pegar o vírus, então tu volta pior do que vai" [...] piorou $100 \%$, foi por causa da pandemia".

Ao ser questionado sobre sua saúde mental, diferentemente do que dissera no início, afirma que mantém suas atividades quando necessário: "Eu não esquento a cabeça, se tiver que sair, eu ando pela rua e volto pra casa”. Em seguida, se justifica sugerindo que é uma situação inesperada e controladora: "Por que é difícil ficar preso, é como se a gente estivesse com uma tornozeleira invisível". Comenta com tristeza: "o cara fica xarope de estar em casa, não ver os amigos, não poder dar um abraço e conversar de perto". E menciona com revolta, desvelando uma crença culpabilizante: "[...] fico com raiva daqueles chineses otários, que comem todos os tipos de porcaria e largaram esse vírus no mundo".

\section{Caso 4}

Carlos menciona diagnóstico de diabetes, hesita ao afirmar ser parte do grupo de risco, mas se considera devido à doença. Reside com a esposa e a filha adulta e tem mais três filhos com quem mantém contato permanente. Também encontra-se com conhecidos, faz visitas a casais de amigos e recebe convidados.

Ele e sua família fizeram adaptações que considera ter virado rotina: "Uso máscara direto, na entrada de casa tem um pano com clorofina, bate os pés, passa álcool em gel em tudo que trás da rua. O supermercado a gente passa spray de álcool antes de guardar, isso já é norma já". Carlos é o único entrevistado que permane- ceu trabalhando durante a pandemia, assim como sua filha e esposa: "Eu sigo normal, não parei com nada, até porque eu tenho que trabalhar, então eu só me cuido mais um pouco". O tom aparente é de adaptação: “[...] ficou diferente só o jeito da gente conviver né, é diferente porque antes era tudo a vontade, hoje tu tem um controle".

O discurso de Carlos*, por vezes, mostra uma sensação de estar apartado da situação: “[...] está tudo normal, eu não tive ninguém próximo com essa doença, então eu não consigo assimilar alguma dificuldade sobre ela". As notícias sobre a pandemia chegam através dos familiares, mas as evita, pois considera que são inseguras e geram mais preocupação: "é muito forte, e eu fico na dúvida se é verdade ou não, é muita coisa". Suas buscas através do celular são esporádicas, pois considera que as informações são excessivas: "[...] eu não procuro pesquisar, porque se a gente começa a escutar muita coisa fica muito fixado naquilo e não consegue manter um nível de vida".

Considera que a pandemia interferiu "bastante mesmo" no seu acesso ao serviço de saúde: "porque eu fazia tratamento, $[\ldots]$ e procurei um particular mas não me acertei”. Diz que não tem tempo suficiente para organizar sua alimentação: "tem coisas que eu estou comendo que não seriam para comer, eu me alimento assim pela correria do dia a dia" e sente falta de praticar atividade física: "eu estou com um problema no joelho [...] estou tentando tratamento, mas com essa dificuldade em conseguir, então estou sem exercício e isso me faz muito mal".

Ao ser questionado sobre sua saúde mental durante a pandemia, de zero a dez, se atribui sete: "[risos], não vamos exagerar". Considera que sentiu tristeza e impotência diante das mortes por COVID-19, uma "desgraça": "[...] pelas pessoas que se vão, é uma coisa que tu não consegue fazer nada por ninguém, então sinto às vezes tristeza por isso".

\section{Análise Cruzada dos Casos}

Além das características próprias de cada caso, a análise segue para a discussão integrada dos mesmos. Os participantes apresentaram características bastante homogêneas, havendo apenas um francamente destoante. Algumas das principais repercussões compartilhadas, e que descrevem as categorias de análise aqui empregadas, foram a sensação de privação de liberdade e isolamento (Distanciamento Social), insegurança nas informações sobre a pandemia (Informação), limitação de acesso aos 
serviços e assistência de saúde (Acesso ao Serviço de Saúde) e aumento das demandas emocionais (Saúde Mental).

Alterações nas rotinas e restrição de atividades cotidianas também foram unânimes. De maneira geral, disseram incluir o uso de máscaras, álcool gel e higienização de produtos e alimentos. A redução de contato físico e de convívio social foram mencionadas com pesar. Frustração e irritabilidade foram vinculadas a redução de autonomia, liberdade e à vigilância e autocontrole impostos pela situação pandêmica, associados à ideia de aprisionamento, confinamento e monitoramento constante.

Frente a essas circunstâncias, utilizaram-se de estratégias de adaptação e enfrentamento à situação. A maioria fez uso das redes sociais e telefone para manter o contato seguro. Mencionam uso de diversos artifícios para lidar com as angústias: conversar em busca de alívio, se utilizar da espiritualidade como refúgio, outros fizeram artesanato, caminhadas e romperam com o isolamento como defesa contra as dificuldades. Os homens foram mais resistentes e mantiveram mais atividades inalteradas durante a pandemia: "se eu tenho que sair eu saio, faço as coisas que tenho que fazer e deu" (Antônio), em especial Carlos que manteve as atividades laborais e o contato presencial com diferentes pessoas.

Um dado importante sobre a saúde mental desta população, são as alterações do sono, relatadas por todos, incluindo o uso de medicamentos para dormir. Apesar de a insônia intensificar-se com a idade, tornando-se mais comum entre os idosos (Gulia \& Kumar, 2018), configura-se como fator de risco para prejuízos ao funcionamento cotidiano. Além disso, a insônia recorrente aumenta o risco de transtornos mentais como a depressão (Chellappa \& Araujo, 2007).

De maneira geral, a situação de moradia e renda, aparece como elemento protetivo, bem como a rede de apoio. Os participantes consideram que tem espaço físico e condições suficientes para suas necessidades e de seus familiares. Também consideram que têm com quem contar em caso de necessidade. Os dados encontrados condizem com a influência que as redes sócioafetivas exercem sobre o desenvolvimento e bem estar subjetivo(Bronfenbrenner, 1996) e com o amplo impacto que as condições materiais e psicossociais (moradia, emprego,renda e o acesso aos serviços de saúde) têm enquanto Determinantes Sociais da Saúde (CNDSS, 2008).

Houve receptividade com as entrevistas, questionamentos sobre mais encontros ou acompanhamento psicológico e a menção de que gostariam de conversar mais vezes. Isso traz indícios da importância do vínculo com o grupo e sugere necessidade de comunicação e suporte durante este período. A potência vincular com o grupo, especialmente por parte das mulheres, é um aspecto interessante pela aparente relação com um senso de pertencimento e representatividade, o fazer parte de um grupo que lhes garante um lugar. Isso diz muito das relações e trocas que estes espaços proporcionam e que vão além do processo educativo. As redes sociais e comunidades são importantes fontes de apoio e fortalecimento para melhorar suas condições de saúde e bem-estar (CNDSS, 2008).

A interrupção do acompanhamento em saúde aparece como fonte de preocupação e medo de diferentes formas, ora como receio de contaminação, ora de não ter acesso e de não receber cuidados adequados ou também como medo da solidão. Segundo o relato dos entrevistados, houve redução de acesso a cuidados em saúde, medicamentos, prescrições e consultas de acompanhamento. E a preocupação com a manutenção de seus tratamentos foi predominante, como a menção de sensação de abandono nos casos de Márcia e Sandra e insatisfação nos casos Antônio e Carlos. O volume e o conteúdo das informações disponíveis sobre a COVID-19 foram considerados excessivos e inseguros e produziram catastrofização, fantasias e medo. Também mencionaram que muitas vezes não souberam como agir. Antônio leva esta questão ao extremo ao descrever uma série de teorias conspiratórias sobre a origem e o propósito do surgimento do vírus causador da COVID-19.

A sensação de instabilidade parece ter sido reforçada pela propagação de informações ambíguas ou falsas em relação à COVID-19 e aos serviços de saúde. Tendo em vista que a ausência de informações e a desinformação atuam como combustível para inseguranças (Wang, Mckee, Torbica \& Stuckler, 2019), a dificuldade de acesso a serviços e educação em saúde contribuem para a redução das opções disponíveis para que as pessoas tomem decisões seguras sobre o próprio bem estar. Aqui, pode-se fazer uso do conceito de "pós-verdade" (Flood, 2016) como a escolha de uma suposta verdade por afetividade, independentemente de comprovação.

As redes sociais, a polarização e o declínio da confiança na ciência contribuem para que a pós-verdade se instale na sociedade (Lewandowsky, Ecker \& Cook, 2017). Bem como o viés cognitivo, que consiste em equívocos 
mentais causados por informações superficiais, permitindo o emprego de estratégias simplificadoras na tomada de decisões. Essas simplificações são frequentemente úteis para ajudar a lidar com complexidades e ambiguidade (Heuer Jr, 1999), como é o caso da atual pandemia. Dessa forma, a população acaba por decidir sobre a realidade de acordo com crenças pré estabelecidas, diminuindo as chances de aceitar fatos comprovados.

Neste caso, os Determinantes Sociais de Saúde comportamentais e de estilos de vida (CNDSS, 2008) precisam ser considerados por sua possibilidade de influenciar as tomadas de decisão, especialmente pela forte carga cultural e emocional que os conteúdos relacionados à saúde disparam. A insegurança nas informações e nas instituições pode tornar-se perigosa, afetando a capacidade de enfrentamento da população, tanto para a manutenção dos cuidados necessários para evitar a contaminação, como para a saúde mental, exacerbando as experiências de sofrimento . As estratégias de educação em saúde e o oferecimento de informações seguras são indispensáveis.

\section{Discussão e considerações}

Os resultados mostram que os fenômenos desta crise podem ser agravados principalmente pela desinformação e interrupção do acompanhamento em saúde, que aparecem como importantes fontes de preocupação e ansiedade. Em contrapartida, a condição socioeconômica, o acesso à cuidados e relações comunitárias satisfatórias, surgem como fatores de proteção para esta população, destacados tanto nas falas dos entrevistados, como também na literatura (Buss \& Pellegrini Filho, 2007).

Quanto às repercussões negativas sobre a saúde mental, foram identificados diferentes níveis de sofrimento. Os resultados obtidos dão pistas de que a pandemia e o distanciamento social ocasionaram significativas mudanças nas rotinas dos participantes, demandando importantes adaptações. Estes dados corroboram com os achados ao redor do mundo (Wang, Pan, Wan, Tan, Xu, Ho, \& Ho, 2020; Hossain, Sultana \& Purohit, 2020), ademais, percebeu-se que, o acesso aos serviços de saúde e à informação de qualidade também são elementos poderosos de influência sobre a saúde mental. Estas são informações importântes tendo em vista sua possível influência sobre o controle das doenças crônicas e a dificuldade em acessar informações seguras sobre a pandemia como já mencionado por HELENA, LASAGNO \& VIEIRA (2010) e KAR et al. (2020).
Destaca-se que o sofrimento psíquico em si não é doença, é preciso avaliar com cuidado as reações em momentos de crise, para não ocorrer patologização e individualização das respostas apresentadas. Ainda assim, o constante medo, preocupação e incerteza durante o surto de COVID-19 podem ter consequências a longo prazo dentre os mais vulneráveis (IASC, 2020). Reconhecer os sinais de alerta para diferenciar quem precisa de ajuda e quem tem recursos de enfrentamento suficientes, é importante para ofertar intervenções direcionadas para as necessidades de cada população.

Dito isso, considera-se pertinente a adoção de medidas de proteção e prevenção ao surgimento de sofrimento mental a partir da compreensão das repercussões da pandemia. Estes dados podem promover subsídios para gestores e profissionais da saúde sobre a importância da oferta de informação segura e produção de alternativas de cuidado que considerem estes impactos a fim de tornar este período menos adoecedor. É preciso repensar as estratégias disponíveis e reinventar os serviços de saúde adaptando-os para o novo contexto. É preciso empregar ferramentas de cuidado para o fortalecimento de indivíduos, famílias e comunidades em face da crise e propor formas alternativas e seguras de manter contato e atividades coletivas.

Espera-se que estes resultados fomentem novas pesquisas sobre o tema, que considerem como as diferentes percepções e as características dos sujeitos e seus contextos podem influenciar a saúde. E também que as discussões propostas contribuam para a produção de conhecimentos sobre a saúde mental e as repercussões da pandemia de COVID-19 e para a qualificação das ações e serviços oferecidos à população.

\section{Referências}

Alves-Mazzotti, A. J. (2006). Usos e abusos dos estudos de caso. Cadernos de Pesquisa, 36 (129), 37-651.

Anderson R. M., Heesterbeek H., Klinkenberg D. \& Hollingsworth T. D., 2020. How will country-based mitigation measures influence the course of the COVID-19 epidemic? The Lancet, 395 (10228), 931-934. Disponível em: https://www.thelancet.com/journals/lancet/article/PIIS01406736(20)30567-5/fulltext. Acesso em: 20 mar. 2020.

Bao, Y., Sun, Y., Meng, S., Shi, J. \& Lu, L (2020). 2019-nCoV epidemic: address mental health care to empower society. The Lancet, 395 (10224), 37-38.

Bardin, L. (2011). Análise de conteúdo. São Paulo: Ed. 70.

Brasil (2018). Ministério da Saúde. Vigilância de Doenças Crônicas Não Transmissíveis (DCNT). Disponível em: Página Inicial - Português (Brasil). Acesso: 18 Mai. 2020.

Brooks S. K., Webster R. K., Smith L. E., Woodland L., Wessely S. \& Greenberg $\mathrm{N}$, et al(2020). The psychological impact of quarantine and how to reduce it: rapid review of the evidence. The Lancet, London, 395, 912-920. 
Buss, P. M. \& Pellegrini Filho, A. (2007). A Saúde e seus Determinantes Sociais. Physis: Revista Saúde Coletiva, Rio de Janeiro, 1 (17), 77-93.

Chellappa, S. L. \& Araujo, J. F. (2007). Sleep and Sleep Disorders in Depression. Revista de Psiquiatria Clínica, Natal, 34 (6), 285-289.

CNDSS - Comissão Nacional sobre Determinantes Sociais da Saúde (2008). As causas sociais das iniqüidades em saúde no Brasil. Rio de Janeiro: Editora Fiocruz.

Fiocruz, Fundação Oswaldo Cruz (2020). Saúde Mental e Atenção Psicossocial durante a Pandemia COVID-19: Recomendações Gerais. Disponível em: Portal UNA-SUS - Especial COVID-19. Acesso em: 15 abr. 2020.

Flood, A. (2016). Post-truth' named word of the year by Oxford Dictionaries. The guardian, 15, 2016. Disponível em: https://www.theguardian.com/ books/2016/nov/15/post-truth-named-word-of-the-year-by-oxford-dictionariesFoster. Acesso em: 01 Fev. 2020.

Guan, W., Ni, Z., Hu, Y. \& Liang, W. et al (2020). Clinical characteristics of coronavirus disease 2019 in China. The new england journal of medicine.

Gulia K. K. \& Kumar M. (2018). Sleep disorders in the elderly: a growing challenge. Psychogeriatrics, 18 (3), 155-165. Wiley.

Helena, E. T. S., Lasagno B. G. S. \& Vieira R. (2010). Prevalência de transtornos mentais não-psicóticos e fatores associados em pessoas com hipertensão arterial sistêmica e/ou diabetes mellitus em Unidades de Saúde da Família em Blumenau, Santa Catarina. Revista Brasileira de Medicina de Família e Comunidade, 5 (17), 42-47.

Heuer Jr. R. J (1999). Analysis of competing hypotheses. Psychology of Intelligence Analysis, 95-110.

Hossain M., Sultana A. \& Purohit N., (2020). Mental health outcomes of quarantine and isolation for infection prevention: A systematic umbrella review of the global evidence. Social Science Research Network, Texas. Disponível em:https: $/ /$ papers.ssrn.com $/$ sol3 $/$ papers.cfm?abstract id $=356126$. Acesso em: 12 abr. 2020.

IASC, Inter-Agency Standing Committee (2020). Nota Informativa Provisional. Como abordar a saúde mental e os aspectos psicossociais da crise da COVID-19. IASC: Geneva.

Jylha, M., Guralnik J. M., Ferruci, L., Jokela, J. \& Heikkinen, E. (1998). Is Self-Rated Health Comparable across Cultures and Genders? The Journals Of Gerontology Series B: Psychological Sciences and Social Sciences, 53 (3), 144-152. Oxford University Press.

Kar, S. K., Arafat, S. M. Y., Kabir, ., Sharma, P. \& Saxena, S. K. (2020). Coping with Mental Health Challenges During COVID-19. Medical Virology: From Pathogenesis to Disease Control, (199-213). Springer Singapore.

Lewandowsky, S., Ecker, U. K. H. \& Cook, J. (2017). Beyond misinformation:
Understanding and coping with the "post-truth" era. Journal of applied research in memory and cognition, 6 (4), 353-369.

Minayo, M. C. S., (2013). O desafio do conhecimento: pesquisa qualitativa em saúde. 13. ed., São Paulo: Hucitec.

OMS, Organização Mundial da Saúde, (2018). Comunicação de riscos em emergências de saúde pública: um guia da OMS para políticas e práticas em comunicação de risco de emergência. Genebra. Disponível em: $\underline{\text { Comu- }}$ nicación de riesgos en emergencias de salud pública: directrices de la OMS sobre políticas y prácticas para la comunicación de riesgos en emergencias. Acesso em: 16 Abr 2020.

OMS, Organização Mundial da Saúde, (2020). Mental Health Considerations during COVID-19 Outbreak. Disponível em: www.ladoaladopelavida. org.br/detalhe-noticia-ser-informacao/covid-19-oms-divulga-guia-com-cuidados-para-saude-mental-durante-pandemia. Acesso em 25 mar. 2020.

OPAS/OMS, Folha Informativa: Transtornos Mentais, (2018). Disponível em: Transtornos mentais - OPAS/OMS | Organização Pan-Americana da Saúde. Acesso em: 17 Abr. 2020.

OPAS/OMS, Folha Informativa COVID-19 (doença causada pelo novo coronavírus), (2020). Disponível em: Folha informativa sobre COVID-19 - OPAS/ OMS | Organização Pan-Americana da Saúde. Acesso em: 28 Mar 2020.

Portugal, F. B., Campos, M. R. Gonçalves D. A., Mari, J. J., Gask, L., Bower P., Dowrick C. \& Fortes S. (2014). Psychiatric morbidity and quality of life of primary care attenders in two cities in Brazil. Jornal Brasileiro de Psiquiatria, 63 (1), 23-32.

Spink, M. J. (2003). Psicologia da saúde: a estruturação de um novo campo de saber. In Psicologia social e saúde: práticas, saberes e sentidos, 29-39. Petrópolis, Rio de Janeiro: Vozes.

Stake, E. R. (2006). Multiple case study analysis. New York: The Guilford Press.

Wang, Y., Mckee M., Torbica A. \& Stuckler D. (2019). Systematic literature review on the spread of health-related misinformation on social media. Social Science \& Medicine, 240 (112552).

Wang, C., Pan, R., Wan, X., Tan, Y., Xu, L., Ho, C. S. \& Ho, R.C. (2020). Immediate Psychological Responses and Associated Factors during the Initial Stage of the 2019 Coronavirus Disease Epidemic among the General Population in China. International Journal Of Environmental Research And Public Health, 17 (1729).

Yin, R. K (2015). Estudo de caso: planejamento e métodos. 5. ed. Porto Alegre: Bookman.

Submetido em: $30-4-2021$

Aceito em: 17-11-2021 